\title{
Long-term effects of therapy on respiratory health
}

\author{
C. Fuhrman*, P. Ernst**, F. Kauffmann*
}

Long-term effects of therapy on respiratory health. C. Fuhrman, P. Ernst, F. Kauffmann. (c)ERS Journals Ltd 1996.

ABSTRACT: Only scant information is available on the long-term consequences to respiratory health of treatment with bronchodilators and oral corticosteroids.

In the present study, we aimed to gain more information about these consequences. We examined 712 men working in the Paris area, by means of a subjective assessment of whether their respiratory health worsened or improved from 1960 to 1972, the decline in forced expiratory volume in one second (FEV1) over this time-period, and mortality from 1972 to 1992 , in relation to respiratory therapy dispensed during a 2 year period in 1970-1971, as recorded in social security reimbursement records.

As expected, subjects with respiratory symptoms or airflow limitation were more likely to have been prescribed respiratory therapy. After accounting for the effect of lung function level and smoking, subjects dispensed inhaled $\beta$-agonists were likely to feel their condition had worsened and had a greater decline in FEV1 from 1960 to 1972 .

Among subjects with airflow limitation who reported asthma or persistent wheeze, having been dispensed oral corticosteroids on an intermittent basis was associated with improved survival (relative risk (RR) $0.32 ; 95 \%$ confidence interval $(95 \% \mathrm{CI})$ : 0.10-0.91) after adjusting for FEV1 level and smoking category.

Our results add to the evidence that regular use of $\beta$-agonist bronchodilators may be associated with adverse effects on respiratory health, whilst intermittent use of corticosteroids may be of long-term benefit.

Eur Respir J., 1996, 9, 436-443.
*INSERM Unité 169: Recherches en épidémiologie, Villejuif, France. **Respiratory Epidemiology Unit, McGill University, Montréal, Canada.

Correspondence: F. Kauffmann INSERM U. 169: Recherches en épidémiologie

16, avenue Paul-Vaillant-Couturier 94807 Villejuif Cedex

France

Keywords: Adverse events

bronchodilators

corticosteroids

drug therapy

respiratory disease

Received: January 91995

Accepted after revision November 191995

P.E. was the recipient of a bursary for French and Quebec exchanges supported jointly by INSERM and the FRSQ.
Strategies for the medical management of asthma and chronic obstructive pulmonary disease (COPD) are evolving rapidly. In asthma, recent studies suggest that the regular and excessive use of inhaled beta-agonists is linked to worsening asthma and an increased risk of lifethreatening episodes $[1,2]$. On the other hand, recognition of the inflammatory nature of asthma has led to the demonstration of the efficacy of inhaled corticosteroids early in the course of disease and in milder patients [3, 4]. Current guidelines for the treatment of asthma insist on the early use of anti-inflammatory therapy with less reliance on bronchodilator therapy $[5,6]$. Potential hazards of regular use of bronchodilators in COPD have been less commonly reported, but such reports do exist [7]. Corticosteroids, both oral and inhaled, are commonly used in the regular treatment of COPD despite only moderate efficacy. Treatment trials of inhaled corticosteroids in COPD are currently underway [8]. However, there are no long-term studies of the potential benefits or adverse effects of corticosteroids, with respect to either their respiratory or systemic sequelae. Of interest is a recent report by SPARROw et al. [9] suggesting that decline in forced expiratory volume in one second (FEV1) over time was related to endogenous corticosteroids; low levels of serum cortisol predicting greater declines in lung function [9].
If possible, avoidance of systemic corticosteroids appears desirable, given their severe adverse effects when used regularly or in high doses. Long-term hazards or benefits of intermittent use of oral corticosteroids both in asthma and COPD are unknown and may be of greater relevance to the use of inhaled corticosteroids, especially as concerns the higher doses recently made available.

Using a pharmacoepidemiological approach, the present study examined the relationship of decline in FEV1 over $12 \mathrm{yrs}$, the subjects' subjective sense of change in respiratory health, and mortality over $20 \mathrm{yrs}$, to the dispensing of respiratory therapy, particularly beta-agonists and oral corticosteroids over a 2 year interval.

\section{Methods}

The subjects in the present study were enrolled in a longitudinal study on the risk factors for chronic obstructive pulmonary disease with two cross-sectional surveys, in 1960 and 1972, and a study of survival to December 31, 1992. The detailed protocol has been described previously [10].

In a first survey conducted in 1960, 1,474 men born in France, aged 30-59 yrs, and working in 11 factories (metallurgical, chemical, printing and flour-milling) in the 
Paris area, were interviewed about their symptoms (but without a question on asthma), smoking habits and occupational history. Subjects were classified as nonsmokers ( $<1$ cigarette $\cdot$ day $^{-1}$ on average), ex-smokers (smokers for more than 1 year, stopped for at least 3 months), moderate smokers $\left(\leq 15 \mathrm{~g}\right.$ tobacco $\left.\cdot \mathrm{day}^{-1}\right)$, and heavy smokers.

In a second survey, conducted in 1972, a proportion of the same men answered the British Medical Research Council/European Coal and Steel Community (BMRC/ ECSC) questionnaire about their symptoms and smoking habits. Persistent wheeze was defined as a positive answer to a query concerning wheeze occurring most days or nights. Chronic bronchitis represents the complaint of cough and sputum for 3 months of the year, for $\geq 2$ yrs. From the 1972 questionnaire, subjects were classified as ever having had asthma according to their response to the question: "Have you ever had attacks of shortness of breath at rest with wheezing ("asthma attacks")?" Of the 1,248 subjects still alive, $1,073(86 \%)$ were reinterviewed, most of them (844) in the factory or in a medical centre, some of them (144) at home, whilst the remainder (85) answered a mail questionnaire. With the exception of those who answered a mail questionnaire, all of the men were interviewed as to their self-assessment of changes in respiratory health by the following question: Overall, since 1960-1961, do you think that your bronchial or respiratory status has changed (independent of the "normal effect of ageing")? If yes: Has it improved? Has it deteriorated? Ninety three percent of subjects answered this question (which corresponds to $73 \%$ of the original subjects who were still alive). Among the 915 men who answered the question, 22\% reported deterioration and 5\% improvement. Two variables were derived from these questions: "worse" (deteriorated versus others) and "better" (improved versus no change, subject with deterioration excluded).

Spirographic measurements were performed with a Cara water-filled spirometer in the sitting position wearing a noseclip in 1960 and in 1972, for those examined at work or in a medical centre. For the men re-examined at home, a dry expirograph (Vitalograph) was used. Spirometric tracings were available for $95 \%$ and $93 \%$ of the men at the first and second surveys, respectively. In 1960, 26\% of the tracings were labelled as poor tracings and in 3\% in 1972. Spirometric test failure may be a marker of poor prognosis [11] and, therefore, poor tracings were not excluded from the present analysis. Poor tracings were not related to age, asthma, smoking, feeling worse or better. Exclusion of poor tracings did not change any conclusion. For each subject, FEV1 values in 1960 and 1972 were adjusted on age and height, using the linear regression from the whole sample expressed as standardized residuals $($ mean $\pm \mathrm{SD}=0 \pm 1)$. Twelve year FEV1 slope $\left(\mathrm{mL} \cdot \mathrm{yr}^{-1}\right)$ was calculated as $12 \times(\mathrm{FEV} 1$ in 1960 minus FEV1 in 1972)/(months between two surveys).

\section{Drug exposure information}

In France, most medical therapy, including prescribed medications are paid for by the social security system. Reimbursement to the subject can be traced through their social security identification number. The individual files containing all prescribed medicines and medical therapies reimbursed during 1970 and 1971 (24 months) were obtained. All prescriptions dispensed during this period were available [12]. Respiratory therapy was defined as prescriptions which included bronchodilators, antitussives, expectorants and chest physiotherapy. For all these prescriptions, the type of bronchodilator prescribed (beta-agonist or theophylline) and the date of dispensing of the respiratory therapy was recorded. Prescriptions for oral corticosteroids and antibiotics were also identified, as well as whether or not these were dispensed on the same date as other respiratory therapy. The following exposure variables were defined: oral corticosteroids (OCS) - all, if any prescription for OCS was found at any time during 1970-1971; OCS with respiratory therapy, if the OCS was dispensed on the same date as respiratory therapy; beta-agonists, if such medication, either in inhaled or oral form, was dispensed at any time during the 2 year period of observation; theophyllines, if any medication of this class was prescribed during the 2 year period; antibiotics, if such a medication was dispensed simultaneously with other respiratory therapy.

Among the 1,073 men re-examined in 1972, social security records were obtained for $715(67 \%)$ of the men. Subjects without social security records included both those for whom the record was empty, that is no therapy was dispensed, and those for whom the record could not be found. These two categories of subjects could not be distinguished and are not included in the analyses. They did not differ significantly from the subjects included in the analyses as to age, smoking or lung function but they did report significantly less chronic bronchitis, asthma, or persistent wheeze. The analyses in the present report have been carried out among 712 men with information available as to a prior history of asthma (by questionnaire) and complete social security records.

From December 31, 1992, vital status was assessed for 682 of these 712 men and $351(51 \%)$ were deceased. Of the 30 men for whom vital status could not be traced for the full 20 yrs (i.e. until the end of 1992), information was available for at least 10 years (i.e. until 1982) for 18 individuals.

\section{Adjustment for disease severity}

When examining the relationship between adverse respiratory outcomes and the use of various therapies in studies other than randomized controlled trials, it is always difficult to dissociate treatment effect from indication bias; that is the treatment identifies the disease and its severity and it is the disease and not the treatment which it incurs which is the actual cause of the adverse outcome. To adjust for disease severity or indication bias in examining the association between the patients' subjective assessment and the type of therapy dispensed, odds ratios were adjusted for FEV1 level and smoking (four classes). The slopes of FEV1 decline were also adjusted for lung function level and smoking, but, in a further attempt to compare subjects of similar disease severity, the effect of having been dispensed antibiotics 
for respiratory indications and work absences of greater than 20 days for respiratory diagnoses during the 12 year period, 1960-1972 were also accounted for. Antibiotics for respiratory diseases were considered categorically; this was considered to be present if during the 2 year period, 1970-1972, a subject had been dispensed more than one prescription for an antibiotic concurrently with another respiratory treatment. Work absences of more than 20 days for respiratory disease were obtained from social security records, which record these and their cause by International Classification of Diseases (ICD) code (ICD 490-496), and were expressed as number of days missed from work. Among the group as a whole, the slopes of FEV1 decline were further adjusted for the report of persistent wheeze, chronic bronchitis and asthma, since the reporting of such may also favour the dispensing of respiratory therapy. Analyses were also carried out stratified according to the report of asthma and the prevalence of airflow limitation. The latter was defined as an FEV1 less than $75 \%$ predicted according to the published equations of QUANJER et al. [13] and using age at mid-point of follow-up.

In the analysis of mortality, adjustment or severity was performed using FEV1 in 1972 (e.g. standardized residuals), i.e. a measure of severity at the start of the period of follow-up relevant to the survival analysis, as well as smoking in two classes (non and ex-smokers versus moderate and heavy smokers combined), antibiotic use and work absences as defined previously. Smoking status in 1960 was used in all analyses, since this was thought to be less affected by subjects quitting smoking for health reasons. For the analysis of FEV1 decline, adjustment for baseline severity was more problematical, since FEV1 was measured on only two occasions, that is in 1960 and 1972, the beginning and end of the period of observation. Adjustment for the initial value (FEV1 in 1960) would create a spurious association with decline in FEV1 because of the phenomenon of regression towards the mean [14, 15]. Therefore, as proposed by FLETCHER et al. [16], and in line with previous analyses [10, 17], the potential relationship of treatment to FEV1 slope was assessed before and after adjustment for the average of initial and final values of FEV1 divided by the cube of height. For homogeneity, the same adjustment was performed in the analysis of the subjective assessment of change in the state of respiratory health between the two surveys.

Statistical analysis included Chi-squared for the significance of prevalence odds ratios, analysis of variance, linear regression, and Cox proportional hazards for survival analysis.

\section{Results}

In 1972, the average age of the subjects included in the present analyses was 56 yrs (range 41-72 yrs). The prevalence of nonsmokers was quite low (table 1), as one might expect in an all male blue collar population more than 30 yrs ago. The most common chronic respiratory symptom was that related to mucus hypersecretion, whilst nearly $11 \%$ of subjects reported a history of asthma at some time. Both beta-agonists and theophylline
Table 1. - Subject characteristics $(n=712)$ including $\beta$ agonists, theophylline and oral corticosteroids dispensed

\begin{tabular}{|c|c|}
\hline \multicolumn{2}{|l|}{ Characteristic } \\
\hline Age in $1972 *$ yrs & $56(9)$ \\
\hline Smoking (1960) $(\mathrm{n}=710) \%$ & \\
\hline Nonsmokers & 14 \\
\hline Ex-smokers & 11 \\
\hline Moderate smokers & 44 \\
\hline Heavy smokers & 31 \\
\hline Respiratory conditions in $1972 \%$ & \\
\hline Chronic bronchitis & 23 \\
\hline Persistent wheeze & 6 \\
\hline Asthma & 11 \\
\hline $\begin{array}{l}\text { FEV1 in } 1972 *(n=638) L \\
\% \text { pred }\end{array}$ & $\begin{aligned} 2.84 & (0.76) \\
91 & (21)\end{aligned}$ \\
\hline $\begin{array}{l}\text { FEV1 slope } 1960-1972 \text {, unadjusted* } \\
(\mathrm{n}=620) \mathrm{mL} \cdot \mathrm{yr}^{-1}\end{array}$ & $44.9(37.9)$ \\
\hline Subjective assessment $1972(\mathrm{n}=626) \%$ & \\
\hline Feels worse & 24 \\
\hline Feels better & 8 \\
\hline Vital status $(31-12-1992)(\mathrm{n}=682) \%$ deceased & 52 \\
\hline Respiratory therapy, any \% & 43 \\
\hline$\beta$-agonists (1970-1971) \% & 8.5 \\
\hline Without oral corticosteroids & 6.5 \\
\hline Without oral corticosteroids, $\geq 2$ prescriptions & 2.5 \\
\hline Theophyllines (1970-1971) \% & 9.3 \\
\hline Without oral corticosteroids & 7.4 \\
\hline Without oral corticosteroids, $\geq 2$ prescriptions & 2.5 \\
\hline Any oral corticosteroid (1970-1971) \% & 10.5 \\
\hline With respiratory therapy & 3.2 \\
\hline With respiratory therapy, $\geq 2$ prescriptions & 1.8 \\
\hline $\begin{array}{l}\text { Antibiotics with respiratory therapy } \\
(1970-1971) \%\end{array}$ & 23.0 \\
\hline$\geq 2$ prescriptions & 9.4 \\
\hline $\begin{array}{l}\text { Sick leave }(\geq 20 \text { days }) \text { for respiratory disease } \\
(1960-1972) \%\end{array}$ & 1.4 \\
\hline
\end{tabular}

*: values are presented as mean, and SD in parenthesis. FEV1: forced expiratory volume in one second; $\%$ pred: percentage of predicted value.

bronchodilators had been dispensed to less than $10 \%$ of the cohort and this was mostly in the absence of any record of corticosteroid use during the 2 year period for which medication records were examined. At least one prescription for OCS had been dispensed to $11 \%$ of subjects and in $3 \%$ this occurred on a prescription containing other respiratory therapy. Only 13 subjects had more than one prescription for OCS and, because medications were rarely dispensed for more than 6 months (usually less than 3 months), treatment with OCS was almost surely intermittent. Subjects were asked whether they felt their respiratory health had changed between the two surveys 12 yrs apart; 24\% felt it had worsened and 8\% of the remainder felt it had improved.

Table 2 demonstrates the relationship between use of two major classes of respiratory medicine, either together or alone, and various indicators of respiratory health as measured in 1972. These combinations of therapy are also used for further analyses. Similar results were obtained if theophyllines were used as the major bronchodilator class instead of the $\beta$-agonists. As one would expect, those subjects with chronic respiratory symptoms, 
Table 2. - Respiratory parameters in 1972 in relation to therapy dispensed during 1970-1971

\begin{tabular}{|c|c|c|c|c|c|c|}
\hline & \multicolumn{3}{|c|}{$\beta$-agonists } & \multicolumn{3}{|c|}{ Oral corticosteroids } \\
\hline & None $\S$ & $\mathrm{All}^{\$}$ & $\begin{array}{c}\text { Without } \\
\text { OCS }\end{array}$ & None ${ }^{\S}$ & $\mathrm{All}^{\$}$ & $\begin{array}{c}\text { With } \\
\text { respiratory therapy }\end{array}$ \\
\hline \multicolumn{7}{|c|}{ Chronic bronchitis } \\
\hline Present/at risk & $135 / 652$ & $28 / 60$ & $21 / 46$ & $142 / 637$ & $21 / 75$ & $10 / 23$ \\
\hline$\%$ & 21 & $47 \ddagger$ & $46^{\ddagger}$ & 22 & 28 & $44^{*}$ \\
\hline \multicolumn{7}{|l|}{ Persistent wheeze } \\
\hline Present/at risk & $34 / 649$ & $10 / 60$ & $7 / 46$ & $39 / 365$ & $5 / 74$ & $3 / 23$ \\
\hline$\%$ & 5 & $17 \ddagger$ & $15^{* *}$ & 6 & 7 & 13 \\
\hline \multicolumn{7}{|l|}{ Asthma } \\
\hline Present/at risk & $53 / 652$ & $24 / 60$ & $13 / 46$ & $55 / 637$ & $22 / 75$ & $14 / 23$ \\
\hline$\%$ & 8 & $40 \div$ & 28 & 9 & $29 \ddagger$ & $61 \div$ \\
\hline \multicolumn{7}{|l|}{ Airflow limitation ${ }^{\dagger}$} \\
\hline Present/at risk & $92 / 584$ & $26 / 47$ & $17 / 35$ & $95 / 568$ & $23 / 63$ & $12 / 20$ \\
\hline$\%$ & 16 & $55 \ddagger$ & $49 \ddagger$ & 17 & $37 \ddagger$ & 60 \\
\hline
\end{tabular}

§: all comparisons are made with the "none" group; $\uparrow:$ FEV1 less than $75 \%$ predicted in 1972. FEV1: forced expiratory volume in one second; OCS: oral corticosteroids. *: $\mathrm{p} \leq 0.05 ; * *: \mathrm{p} \leq 0.01 ;: \mathrm{p} \leq 0.001$; $\$$ : All refers to drug prescribed.

asthma or airflow limitation were more likely to have been dispensed both classes of medication, the only exceptions being the absence of an association between persistent wheeze or chronic bronchitis and the use of corticosteroids. The strongest associations were between asthma and beta-agonist use (odds ratio (OR) 7.40; 95\% confidence interval (95\% CI) 4.39-12.45); airflow limitation and beta-agonist use (OR 6.65; 95\% CI 3.82-11.57); and asthma and use of corticosteroids (OR 4.31; 95\% CI 2.54-7.34). As shown in table 3, subjects who felt improved were more likely to have received either class of medication, but only subjects who had been dispensed beta-agonists felt their respiratory condition had deteriorated from 1960 to 1972 over what they might have expected in relation to advancing age. After adjusting for FEV1 level and smoking in 1960 (four classes), subjects were more than twice as likely to have been dispensed beta-agonists if they felt their condition had worsened (OR 2.10; 95\% CI 1.02-4.34), whilst there was a tendency for the inverse with corticosteroids (OR 0.59; 95\% CI 0.28-1.21). Among subjects who did not feel their health had worsened over the 12 year period, there was a fourfold increase in the likelihood of being dispensed beta-agonists (OR 3.94; 95\% CI 1.33-11.70) if they felt their condition to be improved as well as an approximately twofold, though not statistically significant, increase in dispensing of corticosteroids (OR 2.32; $95 \%$ CI 0.96-5.58).

Figure 1 presents box plots for unadjusted slopes of FEV1 decline according to therapy dispensed, and whether such therapy was observed more than once over the 2 year period during which prescriptions were monitored. FEV1 decline increases for each class of modification dispensed and with the number of prescriptions within each class. As seen in table 4, the unadjusted slopes of decline in FEV1 are on average, approximately $25 \mathrm{~mL} \cdot \mathrm{yr}^{-1}$ greater if subjects were dispensed beta-agonists or corticosteroids in conjunction with other respiratory therapy. The decline in FEV1 is less steep in the group dispensed corticosteroids as a whole as compared to those in whom it was dispensed concurrently with other respiratory therapy, and this suggests that corticosteroids may have been prescribed for nonrespiratory indications among a number of subjects in the former group. After adjusting the FEV1 slope for level of lung function during the study period and for smoking, the excess decline among users

Table 3. - Odds ratios for subjects' assessment of change in respiratory health according to therapy dispensed

\begin{tabular}{|c|c|c|c|c|c|}
\hline & \multicolumn{3}{|c|}{$\beta$-agonists } & \multicolumn{2}{|c|}{ Oral corticosteroids } \\
\hline & None & All & Without OCS & None & All \\
\hline Subjects $\mathrm{n}$ & 535 & 36 & 26 & 514 & 57 \\
\hline Feeling worse $\%$ & 22 & $42 * *$ & $46^{* *}$ & 24 & 18 \\
\hline \multicolumn{6}{|l|}{ Odds ratios } \\
\hline Crude & 1.00 & $2.50 * *$ & $3.00 * *$ & 1.00 & 0.67 \\
\hline Adjusted for FEV1 level ${ }^{\dagger}$ & 1.00 & $2.19 *$ & $2.71 *$ & 1.00 & 0.59 \\
\hline Adjusted for FEV1 and smoking§ & 1.00 & $2.10 *$ & $2.60 *$ & 1.00 & 0.59 \\
\hline Subjects $\mathrm{n}$ & 416 & 21 & 14 & 390 & 47 \\
\hline Feeling better $\%$ & 7 & $29 * *$ & 21 & 7 & $17 *$ \\
\hline \multicolumn{6}{|l|}{ Odds ratios } \\
\hline Crude & 1.00 & $5.15^{* *}$ & 3.50 & 1.00 & $2.65^{*}$ \\
\hline Adjusted for FEV1 level ${ }^{\dagger}$ & 1.00 & $4.22 * *$ & 3.05 & 1.00 & 2.34 \\
\hline Adjusted for FEV1 and smoking§ & 1.00 & $3.94 * *$ & 2.84 & 1.00 & 2.32 \\
\hline
\end{tabular}

$\dagger$ : FEV1 level is the mean of FEV1 values obtained in 1960 and 1972 divided by $\mathrm{Ht}^{3}$; $\$$ : smoking in four classes (none, ex-smoker, moderate, heavy smoker) as reported in 1960. For explanations and abbreviations see legend to table 2 . $*: p \leq 0.05 ; * *: p \leq 0.01$ compared to none group. 


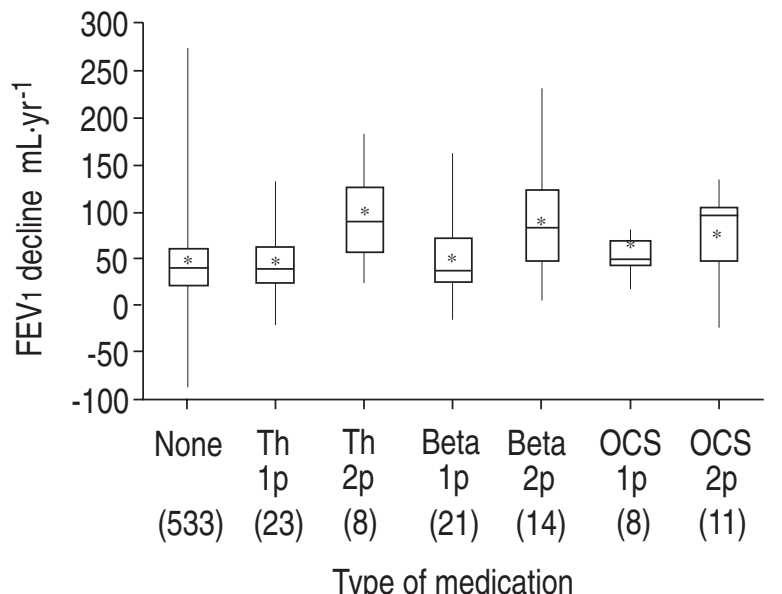

Fig. 1. - FEV1 decline in relation to medication prescribed (boxplots). The figure presents the maximum, minimum, median, interquartile range and the mean $(*)$ of FEV 1 decline in each treatment category. Values in brackets are $\mathrm{n}$. Th: theophylline without beta-agonists or oral corticosteroids. Beta: beta-agonists without oral corticosteroids; OCS: oral corticosteroids with respiratory therapy. 1p, 2p: 1 prescription only, $\geq 2$ prescriptions only, respectively; FEV1: forced expiratory volume in one second.

of beta-agonists and of corticosteroids for respiratory disease is reduced to approximately $15 \mathrm{~mL} \cdot \mathrm{yr}^{-1}$ and remains statistically significant for the users of beta-agonists. Further adjustment for severity of respiratory disease by accounting for exacerbations of disease as measured by the dispensing of two or more courses of antibiotics for a respiratory indication and adjusting for prolonged absences from work because of respiratory illness, as well as the presence of chronic bronchitis, persistent wheeze or asthma, reduced these differences in slope only marginally.
In an attempt to restrict the comparison of the therapies to subjects with respiratory disease, we repeated the comparisons of FEV1 slopes in two subgroups (table 4). Firstly, as expected, the declines in lung function are greater among subjects reporting asthma or persistent wheeze. The differences according to whether or not subjects received beta-agonists are of similar magnitude as in the study population as a whole but the smaller number of subjects in this analysis precludes statistical significance. In contrast, subjects dispensed OCS have less FEV1 decline after adjusting for FEV1 level and smoking, though this is not statistically significant. The greatest declines are to be found among subjects with airflow limitation. These yearly declines are on average larger by $25 \mathrm{~mL}$ or more among those dispensed betaagonists and statistically significant even after adjustment. In contrast, the difference in relation to use of OCS is approximately $10 \mathrm{~mL} \cdot \mathrm{yr}^{-1}$ and not statistically significant.

Relative risks (RR) for all cause mortality in relation to treatment received are shown in table 5. After adjusting for the effects of age, there is a trend for an excess in risk of death in subjects who were dispensed betaagonists especially among those who did not receive OCS (RR 1.51; 95\% CI 0.98-2.31). This trend disappears progressively as one adjusts for the markers of disease severity, FEV1, smoking, antibiotics dispensed, days of sick leave for respiratory disease and report of chronic bronchitis, persistent wheeze or asthma. Interestingly, even prior to adjustment for disease severity, there was no increase in the estimate of RR in relation to the prescription of corticosteroids. Furthermore, as one adjusted for disease severity, the RR decreased below unity so that after adjustment for FEV1, smoking, antibiotic use

Table 4. - Decline in FEV 1 (slope in $\mathrm{mL} \cdot \mathrm{yr}^{-1}$ ) from 1960 to 1972 in relation to therapy dispensed

\begin{tabular}{|c|c|c|c|c|c|c|}
\hline & \multicolumn{3}{|c|}{$\beta$-agonists } & \multicolumn{3}{|c|}{ Oral corticosteroids } \\
\hline & None $^{\dagger}$ & All & Without OCS & None $^{\dagger}$ & All & $\begin{array}{c}\text { With } \\
\text { respiratory therapy }\end{array}$ \\
\hline All subjects $n$ & 572 & 46 & 34 & 555 & 63 & 19 \\
\hline Crude & 43.0 & $68.6^{\ddagger}$ & $68.7^{\ddagger}$ & 43.6 & $56.0 *$ & $68.4 * *$ \\
\hline Adjusted for FEV1 level & 43.5 & $62.0^{\ddagger}$ & $63.2 * *$ & 44.0 & 52.9 & 59.5 \\
\hline and smoking & 41.3 & $59.1 * *$ & $60.7 * *$ & 41.7 & 49.9 & 55.7 \\
\hline and antibiotics dispensed $\$$ & 45.5 & $60.1 *$ & $62.5 * *$ & 47.0 & 53.2 & 55.5 \\
\hline and respiratory sick leave $\mathrm{e}^{\S}$ & 45.0 & 56.3 & $59.2 *$ & 45.7 & 51.6 & 51.8 \\
\hline $\begin{array}{l}\text { and chronic bronchitis, and asthma or } \\
\text { persistent wheeze }\end{array}$ & 48.9 & 57.0 & 59.8 & 49.3 & 55.4 & 54.5 \\
\hline Subjects with asthma or persistent wheeze $n$ & 66 & 20 & 11 & 69 & 17 & 11 \\
\hline Crude & 52.5 & 76.6 & 81.5 & 59.2 & 53.6 & 66.2 \\
\hline Adjusted for FEV1 level & 54.5 & 69.8 & 75.9 & 60.0 & 50.2 & 57.1 \\
\hline and smoking & 58.2 & 71.5 & 78.9 & 62.9 & 53.0 & 55.4 \\
\hline Subjects with airflow limitation ${ }^{+} n$ & 45 & 22 & 14 & 53 & 14 & 10 \\
\hline Crude & 58.0 & $92.0 * *$ & $97.8 * *$ & 65.6 & 82.8 & 77.8 \\
\hline Adjusted for FEV1 level & 57.7 & $92.8 * *$ & $97.9 * *$ & 65.6 & 83.0 & 77.8 \\
\hline and smoking & 55.6 & $89.2 *$ & $95.2 *$ & 61.3 & 75.7 & 70.8 \\
\hline
\end{tabular}

FEV1 level and smoking are defined as in table 3. + : FEV1 slope in the "none" group is derived from the model with all $\beta$-agonists or all corticosteroids. The slopes for the groups $\beta$-agonists without OCS and corticosteroids with respiratory therapy are compared to "none" groups derived from models containing these variables. The slopes from the "none" group in these models may differ moderately from that shown; \$: more than one prescription of antibiotics with respiratory therapy dispensed over the 2 yrs during which prescription records were examined (1970-1971); $\$$ : total number of days of sick leave for respiratory disease of 20 days or more each over 12 yrs (1960-1972); +: airflow limitation is defined as mean of FEV1 in 1960 and 1972 of less than $75 \%$ predicted for age calculated at mid-point of follow-up. For abbreviations see legend to table 2 . *: $\mathrm{p} \leq 0.05 ; * *: \mathrm{p} \leq 0.01 ; \ddagger: \mathrm{p} \leq 0.001$ compared to none group. 
Table 5. - Relative risks for all-cause mortality in relation to therapy dispensed

\begin{tabular}{|c|c|c|c|c|c|c|}
\hline & \multicolumn{3}{|c|}{$\beta$-agonists } & \multicolumn{3}{|c|}{ Oral corticosteroids } \\
\hline & None & All & Without OCS & None & All & $\begin{array}{l}\text { With respiratory } \\
\text { therapy }\end{array}$ \\
\hline \multicolumn{7}{|l|}{ All subjects } \\
\hline Number at risk & 571 & 46 & 34 & 554 & 63 & 19 \\
\hline Number deceased & 270 & 30 & 23 & 226 & 34 & 11 \\
\hline \multicolumn{7}{|l|}{ Relative risks } \\
\hline Adjusted for age & 1.00 & 1.38 & 1.51 & 1.00 & 1.02 & 0.99 \\
\hline and FEV 1 in $1972^{\dagger}$ & 1.00 & 1.10 & 1.26 & 1.00 & 0.88 & 0.79 \\
\hline and smoking ${ }^{\circ}$ & 1.00 & 1.05 & 1.20 & 1.00 & 0.85 & 0.76 \\
\hline and antibiotics dispensed $\$$ & 1.00 & 1.00 & 1.13 & 1.00 & 0.81 & 0.64 \\
\hline and respiratory sick leave $e^{\S}$ & 1.00 & 0.93 & 1.01 & 1.00 & 0.77 & 0.55 \\
\hline $\begin{array}{l}\text { and chronic bronchitis, and asthma or } \\
\text { persistent wheeze }\end{array}$ & 1.00 & 0.90 & 0.96 & 1.00 & 0.80 & 0.57 \\
\hline \multicolumn{7}{|l|}{ Subjects with asthma or persistent wheeze } \\
\hline Number at risk & 65 & 20 & 11 & 69 & 17 & 11 \\
\hline Number deceased & 32 & 13 & 8 & 36 & 9 & 6 \\
\hline \multicolumn{7}{|l|}{ Relative risks } \\
\hline Adjusted for age & 1.00 & 1.20 & 1.96 & 1.00 & 0.82 & 0.71 \\
\hline and $F E V 1$ in $1972^{\dagger}$ & 1.00 & 0.94 & 1.61 & 1.00 & 0.70 & 0.52 \\
\hline and smoking & 1.00 & 0.83 & 1.41 & 1.00 & 0.65 & 0.49 \\
\hline \multicolumn{7}{|c|}{$\begin{array}{l}\text { Subjects with asthma or persistent wheeze and } \\
\text { airflow limitation }{ }^{+}\end{array}$} \\
\hline Number at risk & 25 & 16 & 8 & 31 & 10 & 9 \\
\hline Number deceased & 15 & 12 & 7 & 21 & 6 & 5 \\
\hline \multicolumn{7}{|l|}{ Relative risks } \\
\hline Adjusted for age & 1.00 & 0.93 & 1.63 & 1.00 & 0.56 & 0.46 \\
\hline and $F^{2} V_{1}$ in 1972 & 1.00 & 0.83 & 1.48 & 1.00 & 0.49 & 0.38 \\
\hline and smoking & 1.00 & 0.63 & 1.08 & 1.00 & 0.41 & $0.32 *$ \\
\hline
\end{tabular}

$\uparrow$ : FEV1 in 1972 is expressed as residuals from the linear regression model on age in height for all subjects; ${ }^{\circ}$ : smoking is defined categorically in 2 classes, non and ex-smokers as opposed to moderate and heavy smokers; $\$$ : more than one prescription of antibiotics with respiratory therapy dispensed over the 2 yrs during which prescription records were examined (1970-1971); $\$$ : total number of days of sick leave for respiratory disease of 20 days or more each year over 12 yrs (1960-1972); +: airflow limitation is defined as FEV1 in 1972 less than $75 \%$ predicted. For abbreviations see legend to table 2 . *: $\mathrm{p}=0.03$ compared to none group.

and respiratory sick leave, as well as the report of chronic bronchitis, asthma or persistent wheeze, the best estimate of effect suggested, if anything, a decreased risk of death among those prescribed OCS with concomitant respiratory therapy (RR 0.57 ; 95\% CI $0.27-1.19$ ). These patterns were more pronounced in the analyses limited to subjects with asthma or persistent wheeze (RR 0.49 ; 95\% CI 0.19-1.25) as well as among those with airflow limitation in 1972 (RR 0.46; 95\% CI 0.17-1.24) after adjustment for FEV1 level and smoking. In the further subset of subjects with both asthma or persistent wheeze and airflow limitation, which might be expected to benefit most from therapy, and after adjusting for FEV 1 and smoking, the protective effect of having been dispensed OCS with concomitant respiratory therapy achieves statistical significance (RR 0.32 ; 95\% CI 0.10-0.91).

\section{Discussion}

Long-term prognosis in relation to use of bronchodilators and oral corticosteroids was examined over a 2 year period (1970-1972) among 712 middle-aged men who underwent spirometry in 1960 and again in 1972 and whose vital status was ascertained to December 31, 1992. Despite the expectation that OCS might have been used preferentially among subjects with more severe respiratory disease, those who were dispensed OCS did not feel that their health had significantly deteriorated over a 12 year interval, did not demonstrate a greater decline in FEV1 and did not experience a greater mortality from 1972 to the end of 1992. Among a subset thought to be most likely to benefit from treatment with OCS, those who report persistent wheeze or asthma and had airflow limitation by spirometric criteria, treatment with OCs was associated with a significant reduction in all-cause mortality. On the other hand, subjects dispensed beta-agonist bronchodilators showed subjective deterioration more frequently and had declines in FEV1 over time which were excessive, especially among those with airflow limitation and if OCS were not dispensed over the same period.

The associations described are not necessarily causal. Medications were prescribed to subjects with respiratory complaints so that the prescription of bronchodilators might have been a consequence of the severity of the disease rather than the cause. Such indication bias is difficult to control outside of a randomized, controlled trial. An attempt was made to account for disease severity in several ways. In the assessment of subjective change and lung function decline over the 12 year period the association with medications dispensed was adjusted for 
the level of lung function and for smoking. A limitation of the adjustment for baseline severity was the availability of only two measures of FEV1 obtained at the beginning and end of the follow-up period. Whilst epidemiologically it would appear most appropriate to account for differences in severity of respiratory disease among subjects on the basis of initial value, this creates a spurious association with decline in FEV1 due to the phenomenon of regression towards the mean [15]. Adjustment for severity was, therefore, carried out using the mean of the initial and final values of FEV1 divided by the cube of height.

In examining lung function decline over time among all subjects (this could not be done in the subgroup analyses because of the small number of subjects and resultant instability of the statistical models), further adjustment for disease severity was attempted by accounting for the presence of an excess of acute exacerbations as signalled by the dispensing of two or more antibiotic prescriptions. for the number of days of sick leave taken for prolonged respiratory illnesses over the 12 year period and for the report of chronic respiratory symptoms. After this last adjustment, the association with the dispensing of betaagonists was no longer statistically significant. These adjustments for disease severity reduced the lung function decline among those dispensed OCS so that no excess was demonstrable, and there was a suggestion of a reduction in mortality in certain analyses. Whilst this might be attributable to a protective effect of OCS especially among those with more severe disease, indication bias might also explain these findings.

As seen in table 2, 60\% of subjects who were dispensed OCS in conjunction with other respiratory therapy reported a prior diagnosis of asthma. This was approximately twice the prevalence of asthma reported by those dispensed beta-agonists but not OCS. BuRRows et al. [18] reported significantly less FEV1 decline over time among subjects whose airflow limitation appeared to be asthmatic in origin as opposed to those whose profile was more that of emphysema. In the study by BuRRows et al. [18] however, the differences in prognosis may have been related to the fact that only smokers were included in the emphysema group and nonsmokers in the asthma group, which was not the case in the present study.

As mentioned previously, when these men were asked whether their health had worsened or improved over a 12 year interval, more subjects dispensed beta-agonists felt their health had deteriorated, while this was not the case among those dispensed OCS. Among those who felt their health had not deteriorated, and after adjusting for lung function level and smoking, the use of beta-agonists was associated with a fourfold greater likelihood of feeling improved, though this was less pronounced if subjects had not received OCS during the period that prescription records were available. This again points to inhomogeneity in the response of patients to various treatment regimens, which is not surprising given the often poor distinction between various bronchial pathologies.

In interpreting the results presented, we are assuming that the therapy received over a 24 month period at the end of the follow-up of FEV1 and just prior to the 20 year follow-up of mortality is somehow representative of therapy throughout these periods of follow-up. There are likely to be substantial inaccuracies in this assumption. We do feel, however, that subjects treated with bronchodilators or with OCS during 1970-1971 are more likely to have received such medications both before and after the 2 year period for which the social security records were examined. Misclassification of exposure is likely to be otherwise random and would diminish, not exaggerate, the associations described. For the period when the social security records were examined, the information is very accurate since it represents medications actually dispensed to individuals and for which they obtained reimbursement.

The patterns of therapy described pertain to a period more than 20 yrs ago and one can question whether this information is of relevance to the current therapy of chronic respiratory disease, including both asthma and chronic obstructive bronchitis related to smoking. The beta-agonists available at the time were isoproterenol and salbutamol, the latter introduced in France early in 1971. Whilst the cardiac toxicity of isoproterenol is greater than the newer beta $_{2}$-selective bronchodilators, their relationship to FEV1 decline is more likely to be related to chronic bronchodilation than to any specific effect of different bronchodilators [7]. This interpretation is further supported by analyses not detailed in the present report which demonstrate similar associations when examining theophylline type bronchodilators. As for the information on the use of OCS, it appears that during the 2 yrs of observation and based on the small number of multiple prescriptions, OCS were used intermittently, probably for acute exacerbations, which is very similar to their use today. It remains probable that a proportion of subjects were taking low doses for prolonged periods, but we are unable to determine this. Such low dose therapy with OCS in chronic nonspecific lung disease (CNSLD) has previously been reported to be associated with improved prognosis over a prolonged period of time $[19,20]$. Low dose therapy with OCS may also have relevance to current therapy with inhaled corticosteroids, which has been associated with improved prognosis both in asthma [3, $21]$ and possibly COPD [4, 22]. For chronic airflow obstruction not related to asthma, however, the evidence for beneficial effects for long-term corticosteroids remains to be clearly demonstrated [23], and is the topic of ongoing trials [8]. These findings are consistent with our results, which suggest that the clearest benefit of therapy with corticosteroids is found among those with a diagnosis of asthma or the report of persistent wheeze.

It must be pointed out that the current study included only middle-aged men working in an industrial environment, the great majority of whom were smokers at some point in time. Our results are certainly not applicable to children and their generalizability to women is unknown.

The value of the present study is the prolonged follow-up of lung function, achieved previously only by the two studies from Postma and co-workers [19, 20], the availability of information on mortality over a 20 year 
period and the coherence of the findings. Such information is unlikely to be obtained by clinical trials. Furthermore, the risks and benefits of bronchodilators and OCS were similar in direction whether ascertained by the subject himself, observed decline in lung function over time, or mortality ascertained over 20 yrs of observation.

Acknowledgements: The authors wish to thank D Brille who initiated the study, J.C. Sournia from the Caisse Nationale d'Assurance Maladie and J. Bahi for their help in setting up the analysis of social security records, the mayors of the various cities who helped to record mortality data J. Lellouch for helpful discussions on statistical issues, J. Gordon for preparing the manuscript, and all the men who participated in the study.

\section{References}

1. Sears MR, Taylor DR, Print CG, et al. Regular inhaled beta-agonist treatment in bronchial asthma. Lancet 1990; 336: 1391-1396.

2. Spitzer WO, Suissa S, Ernst P, et al. The use of $\beta$-agonists and the risk of death and near death from asthma. N Engl J Med 1992; 326: 501-506.

3. Haahtela T, Jarvinen M, Kava T. Comparison of a $\beta_{2^{-}}$ agonist, terbutaline, with an inhaled corticosteroid, budesonide, in newly detected asthma. N Engl J Med 1991; 325: 388-392.

4. Kerstjens HAM, Brand PLP, Hughes MD, et al. and the Dutch Chronic Nonspecific Lung Disease Study Group. A comparison of bronchodilator therapy with or without inhaled corticosteroid therapy for obstructive airways disease. N Engl J Med 1992; 327: 1413-1419.

5. International consensus report on diagnosis and treatment of asthma. Eur Respir J 1992; 5: 601-641.

6. British Thoracic Society. Guidelines on the management of asthma. Thorax 1993; 48 (Suppl.) 1-24.

7. Van Schayck CP, Dompeling E, Van Herwaarden CLA et al. Bronchodilator treatment in moderate asthma or chronic bronchitis: continuous or on demand? A randomised controlled study. Br Med J 1991; 303: 1426-1431.

8. Pauwels RA, Löfdahl CG, Pride NB, Postma DS, Laitinen LA, Ohlsson SV. European Respiratory Society study on chronic obstructive pulmonary disease (EUROSCOP): hypothesis and design. Eur Respir J 1992; 5: 1254-1261.

9. Sparrow D, O'Connor GT, Rosner B, Demolles D, Weiss ST. A longitudinal study of plasma cortisol concentration and pulmonary function decline in men: the normative aging study. Am Rev Respir Dis 1993; 147: 13451348 .

10. Kauffmann F, Drouet D, Lellouch J, Brille D. Twelve years spirometric changes among Paris area workers. Int J Epidemiol 1979; 8: 201-212.

11. Becklake MR. Epidemiology of spirometric test failure. Br J Ind Med 1990; 47: 73-74.

12. Kauffmann F, Bahl J, Brille D. Méthode d'étude des dossiers d'assurance maladie en épidémiologie. Exemple d'application à propos d'une enquête sur le pronostic de la bronchite chronique. Rev Epidemiol Santé Publique 1976; 24: 437-448.

13. Quanjer PhH (ed), Dalhuijsen A, Van Zomeren BC. Summary equations of reference values. Standardized lung function testing. Bull Eur Physiopathol Respir 1983; 19 (Suppl.): 45-51.

14. Kauffmann F, Brille D, Lellouch J. Factors related to FEV1 slope between two cross-sectional surveys 1960-1972. Scand J Respir Dis 1976; 57: 313-316.

15. Oldham PD. A note on the analysis of repeated measurements of the same subjects. J Chron Dis 1962; 15: 969-977.

16. Fletcher C, Peto R, Tinker CM, Speizer FE. The natural history of chronic bronchitis and emphysema. Oxford, Oxford University Press, 1976.

17. Kauffmann F, Drouet D, Lellouch J, Brille D. Occupational exposure and 12 year spirometric changes among Paris area workers. Br J Ind Med 1982; 39: 221-232.

18. Burrows B, Bloom JM, Traver GA, Cline MG. The course and prognosis of different forms of chronic airways obstruction in a sample from the general population. $N$ Engl J Med 1987; 317: 1309-1314.

19. Postma DS, Steenhuis EJ, van der Weele LTh, Sluiter HJ. Severe chronic airflow obstruction. Can steroids slow down progression? Eur J Respir Dis 1985; 67: 56-64.

20. Postma DS, Peters I, Steenhuis EJ, Sluiter HJ. Moderately severe chronic airflow obstruction. Can corticosteroids slow down obstruction? Eur Respir J 1988; 1: 22-26.

21. Ernst P, Spitzer WO, Suissa S, et al. Risk of fatal and near-fatal asthma in relation to inhaled corticosteroid use. J Am Med Assoc 1992; 268: 3462-3464.

22. Dompeling E, van Schayck CP, van Grunsven PM, et al. Slowing the deterioration of asthma and chronic obstructive pulmonary disease observed during bronchodilator therapy by adding inhaled corticosteroids: a 4 year prospective study. Ann Intern Med 1993; 118: 770-778.

23. Callahan CM, Dittus RS, Katz BP. Oral corticosteroid therapy for patients with stable chronic obstructive pulmonary disease. Ann Intern Med 1991; 114: 216-223. 